\title{
Application of Humanistic Conception in Ideological and Political Work of Enterprises
}

\author{
Xiaoge Duan \\ The Business College of Shaanxi Institute of International Trade and Commerce, Xi'an Shaanxi, \\ 712046, China
}

Key words: People-oriented concept, Enterprises, Ideological and political work.

\begin{abstract}
People-oriented thought is a concentrated embodiment of the fundamental purpose and governing idea of Chinese Communist Party. Ideological and political work of enterprises must implement people-oriented concept, deepen the understanding of people-oriented concept, realize, maintain and develop fundamental interests of employees, educate, guide and inspire employees and respect, understand and care about them. Ideological and political work of enterprises can actually realize its objectives and promote sustainable development of enterprises only by adhering to people-oriented concept and serving employees based on development pace of the current era. This paper describes the necessity of applying people-oriented concept to ideological and political work of enterprises and puts forward countermeasures for the application of people-oriented concept in ideological and political work of enterprises from different perspectives.
\end{abstract}

\section{Introduction}

Currently, the main task of ideological and political work of enterprises is to unite and guide employees according to basic line, guidelines and policies of our Party and objectives of various operating management activities of enterprises under the right leadership of the superior department of Party committee, establish the correct people-oriented concept, unite as one in a concerted effort and make unremitting efforts for realizing work objectives of enterprises in the development process of enterprises. People are not only the fundamental of all objectives in the society, but also the power source of realizing objectives. Similarly, as the fundamental of enterprise development, employees are also an important source of power of enterprise development. Enterprise development cannot be separated from employees. Employees can promote further innovation and development of enterprises and thereby create more and better wealth for the society. It is thus clear that adhering to people-oriented concept is a fundamental starting point for the implementation of ideological and political work by modern enterprises.

\section{Necessity of applying people-oriented concept to ideological and political work of enterprises}

\section{Apply people-oriented concept and make ideological and political work of enterprises targeted}

Ideological and political work of enterprises must be sensible and reasonable. Being sensible means that the mentality of ideological and political work objects should be grasped more accurately. Therefore, ideological and political workers of enterprises must be sincere and communicate with employees with full enthusiasm while taking with employees. Once employees have any fault in work and ideological fluctuation or meet various troubles in life, ideological and political workers of enterprises should give a hand to them with enthusiastic, positive and active attitude and should never escape due to personal busy work to avoid a sense of isolation from employees or evade with any 
excuse which will cause strangeness to employees. Instead, they should make friends with employees. Second, they should resolve contradictions gradually by giving a warm hand and talking in a calm mood with enthusiastic words. They can know the truth only through communication with employees between hearts. Multiple forms such as symposium, respective heart-to-heart talk and analysis on thought of enterprise employees can be taken so as to understand the ideological situation of employees, issues that they most care about, their attitude towards various policies of enterprise and their inner thought, answer questions and strengthen their understanding of enterprise management and reform work of the company so that they can be engaged in enterprise reform work more consciously.

\section{Apply people-oriented concept and make ideological and political work of enterprises produce actual effect}

Ideological and political workers of enterprises should pay attention to the thought of employees positively, summarize and publicize advanced ideology of employees in time, educate and guide employees with specific tangible cases, motivate their initiative of improving their own quality, and carry out characteristic diversified activities to educate employees; organize and guide employees to develop characteristic, creative and positive activities with strong political atmosphere frequently during holidays and festivals based on the current situation and task, such as review of oath at CPC joining ceremony, Party affairs knowledge competition and Party building lecture; meanwhile implement rich enterprise cultural activities good for physical and psychological health of employees, teach through lively activities and spare no effort to realize mutual combination of ideological and political work and enterprise cultural activities; apply enterprise cultural construction comprehensively and strengthen cultural construction of enterprises positively; pay attention to people-oriented thought and integrate ideological and political education, institutional improvement and incentive system with cultural management in the process of enterprise cultural construction, which is an important entry point for ideological and political work of enterprises to serve central work. It is required to highly unify the development of enterprises and that of people, endeavor to realize close connection between ideological and political work of enterprises and economic development, encourage enterprise employees to establish correct outlook on life and value and lofty ideal and belief and make their ideology of loving the country and the enterprise sublimated.

\section{Thinking on countermeasures for applying people-oriented concept to ideological and political work of enterprises}

\section{Ideological and political work of enterprises must have thought innovation with Scientific Outlook on Development}

Contents of ideological and political work are not changeless. Instead, contents and working methods are constantly improved with new tasks under the new situation and continuous improvement of material, cultural and living standard of the masses. To make ideological and political work of enterprises actually realize mutual unification of scientificalness and truthfulness, serviceability and integration, and democracy and popularity, ideological and political workers of enterprises should deeply study and discuss the new situation, cope with various new problems, arm people with scientific theory, guide people with correct public opinion and cultivate people with excellent way. Meanwhile, attention should be paid that simple administrative order or ideological and political work is not an ideal way for implementing enterprise employee management. Ideological and political construction is a vital factor in enterprise cultural system. Enterprise culture is the sum of material culture and spiritual culture of enterprises as well as the reflection of overall quality of enterprise employees. Party building is an important means to guarantee new development of enterprises. Therefore, Scientific Outlook on Development must be used to innovate ideological and political work of enterprises. 


\section{Ideological and political work of enterprises should implement humanistic care and psychological counseling for employees}

People-oriented concept is a reflection of basic features of ideological and political work of enterprises and an essential requirement. The object of ideological and political work of enterprises is people and its main task is to solve the problem of ideological understanding met by people. Once separated from people, ideological and political work of enterprises will become water without a source naturally. While deviating from people-oriented basic requirements, ideological and political work will lose the significance of implementation. Meanwhile, people are an decisive factor in enterprise production process. As long as ideological and political work under people-oriented concept can be done well and vividly, subjective initiative of enterprise employees can be stimulated. Enterprises should pursue for development and benefit. Their development ability of improving productivity is naturally guaranteed. It is required to not only persist in educating, guiding and encouraging people, but also respect, understand and care about people, enrich the spiritual world of enterprise employees, meet their spiritual demands, promote the comprehensive and harmonious development of people and accelerate the formation of harmonious interpersonal relationship. Caring about people means understanding what employees are thinking. It is required to not only implement teaching of situation and task, but also care about the life of difficult employees and vulnerable groups and carry out activities of poverty relief. Understanding people means being good at transpositional consideration, gathering up hearts with emotion and allowing students to identify the development direction, improve self-confidence in work and stimulate inner driving power through heart-to-heart communication. Ideological and political work of enterprises should not only convince people by reasoning, but also touch people with emotion so as to penetrate into the inner heart of employees, produce great inspiring effect, stimulate the sense of responsibility of employees as owner and allow them to make contributions to the sustainable development of enterprises.

Enterprises should care about and be kind to employees comprehensively and at multiple levels. Heart-to-heart talk with employees is an effective method for implementing emotion communication. Enterprises should open their mind and touch and inspire employees sincerely in the process of heart-to-heart talk. While having a heart-to-heart talk with employees, enterprise managers must put themselves in a right position, take a correct attitude, master corresponding skills, treat people sincerely and be understanding. They should have transpositional thinking frequently and feel for others and never be commanding and overwhelm others by their own power; change the sermonic method thoroughly and conduct creative application, move people with the feeling with heuristic methods such as two-way teaching method, discussion-type teaching method and interactive teaching method, understand the emotion of employees and their situation, treat them differently according to each individual and create a united, consistent, equal, harmonious and good cultural environment. Only with smooth mood can employees give play to initiative better. Therefore, efforts should be made in the following three aspects: first, establish employee information collection and feedback system, strengthen their mentality monitoring, evaluation and early warning and improve their mentality counseling system and work balance system so as to realize a smooth way for emotional communication of employees, avoid adverse mentality accumulation and realize positive change of employees' mentality and comprehensive and harmonious development of enterprises. Second, strengthen psychological health education of enterprise employees. It is required to advocate the concept of making efforts positively among enterprise employees, create harmonious spirit and lead employees to handle problems with harmonious method and way of thinking positively. This should reflect the important function of culture and art for physical and mental pleasure. More healthy and richer cultural life should be used to adjust the emotion and psychology of enterprise employees, eliminate their depression and sense of loss and allow them to have adequate material satisfaction and spiritual enjoyment. Third, attention should be paid to employees' feeling and demand in multiple aspects. Great importance should be attached to the subjective feeling of enterprise employees and they should be guided to strengthen their culture positively. Enterprise employees should specify objectives according to their actual situation and get a sense of happiness from work. 


\section{Ideological and political work of enterprises should greatly improve the quality of employees}

Quality improvement of enterprise employees is an important systematic project mainly with the following meanings: first, improvement of moral construction, mainly reflected in the morality and family ethic moral idea of enterprise employees. We emphasize the strengthening of ideological and political construction of enterprises. The acting point of strengthening ideological and political work is to use the right world outlook, value and outlook on life to educate and inspire people, encourage employees to forge ahead with reasonable methods and allow enterprise employees to transform their world outlook in continuous pursuit, develop good value and morality, maintain the image of enterprises better, abide by social public morality more consciously, conduct themselves in good faith and work honestly. Second, improvement of cultural and scientific level. This mainly involves the improvement of service ability of enterprise employees. The emphasis of improving the quality of enterprise employees is to identify where to start. Previous ideological and political work of enterprises often paid great attention to the stimulation of employees' enthusiasm in work and has made good achievements. However, the initiative of people is not utilized completely and effectively. Their initiative becomes a wasted resource. Once histories experienced by us are divided into each relatively independent fragment, we can find previous high enthusiasm and dedication for career. However, the history formed by the connection of fragments above fails to realize the expected objective or produce a result to the satisfaction of ideological and political workers of enterprises. The reason is that work enthusiasm of employees is not confined to a scientific and standardized procedure and is consumed on the pursuit for objectives lacking value. Therefore, ideological and political work of enterprises must get rid of the simple practice stimulating work enthusiasm of people and focus on how to meet the sense of achievement of employees and realize scientific management of their value on the basis of improving the quality of employees.

\section{Ideological and political work of enterprises should create a good external environment for its own development}

Ideological and political work of enterprises should closely connect production and operation management situation of enterprises, the individual growth of enterprise employees, their production and life and various advanced model characters emerging in enterprises and conduct more sensible and reasonable publicity so that enterprise employees can actually feel that they are the owner of the enterprise. It is required to always conform to people-oriented concept and strengthen the establishment of enterprise culture. Enterprise culture is the spirit of an enterprise as well as its soul, which has vital influence on its future development. For enterprises, production and operation belong to hard power, while enterprise culture belongs to soft power. Hard power and soft power supplement each other and cannot be separated. Enterprise development is the development of enterprise employees. The overall mental state, civilization level and creativity of employees will directly determine the development progress and quality of enterprises. Enterprise culture and the growth of enterprise employees have a proportional relationship. Comprehensive quality development of enterprise employees and the development level of enterprises also have a proportional relationship. Therefore, ideological and political work of enterprises should create a good external environment for its own development.

\section{Conclusion}

In conclusion, adhering to people-oriented concept is the core task in ideological and political work of modern enterprises. Enterprises must endeavor to be adapted to ideological and political work under the new situation, think more deeply about how to improve and promote innovative development of ideological and political work of enterprises so as to unify the thought and action of employees in the important career of promoting enterprise reform and development and make their own efforts in order to continue to promote harmonious development of enterprises. 


\section{References}

[1] Ling Liqiong. Innovation of New Mechanism of Ideological and Political Work of Enterprises with People-oriented Concept, Guangxi Electric Undertaking, 2010 (7).

[2] Chen Liping. Thinking on Strengthening and Improving Ideological and Political Work of Enterprises, Journal of Chifeng College (Philosophy and Social Science Edition), 2009 (6).

[3] Liu Xinjian. Discussions on People-oriented Concept in Ideological and Political Work of Enterprises, Success (Education Edition), 2009 (5).

[4] Tang Zhicheng. Establishment of Harmonious Enterprises with People-oriented Concept, Shanghai Rural Economy, 2008 (4).

[5] Cui Jinghua. Discussions on Core of Current Ideological and Political Work of Enterprises People-oriented Concept, New West, 2009 (2).

[6] Hua Yanling. Application of People-oriented Concept in Ideological and Political Work of Enterprises, Guide to Business, 2011 (1). 